\title{
GALLSTONE DISEASE AND CHOLESTEROLOSIS IN MONOZYGOTIC TWIN SISTERS
}

\author{
Ivanchenkova RA ${ }^{1}$, Sharashkina $\mathrm{NV}^{1}$, Martirosyan $\mathrm{IA}^{2, *}$, \\ Limborska $\mathrm{SA}^{3}$, Ryskov AP ${ }^{2}$
}

\begin{abstract}
*Corresponding Author: Dr. Irena A. Martirosyan, Institute of Gene Biology, Russian Academy of Sciences, Moscow, Russia 119334; Tel.: +7-095-135-98-64; Fax:+7-095-135-41-05; Irena-M@ yandex.ru
\end{abstract}

\begin{abstract}
Gallstone disease and cholesterolosis may be independent diseases or forms of the same disease, caused by impairment of cholesterol metabolism. Gallstone disease is characterized by formation of cholesterol concrements in the gallbladder cavity. Cholesterolosis is a hyperplastic cholecistosis, caused by cholesterol accumulation in the gallbladder wall with subsequent proliferation of gallbladder normal tissue elements. We describe monozygotic twin sisters, one of whom developed gallstone disease and the other developed cholesterolosis. Monozygosity was verified by a DNA fingerprinting method. Both had identical heterogeneity of plasma low density lipoprotein (LDL) subfractions, but associated with different functional conditions within the gallbladder. The different manifestations may be due to epigenetic, metabolic or environmental factors, since both had a common genetic basis.

Key words: Cholesterolosis; DNA fingerprinting; Gallstone disease; Monozygotic twin sisters; Multifactorial disorders
\end{abstract}

\section{INTRODUCTION}

Gallstone disease and cholesterolosis have many common etiologic factors. Gallstone disease is

\footnotetext{
1 Moscow Sechenov Medical Academy, Moscow, Russia

${ }^{2}$ Institute of Gene Biology, Russian Academy of Sciences, Moscow, Russia

${ }^{3}$ Institute of Molecular Genetics, Russian Academy of Sciences, Moscow, Russia
}

characterized by formation of cholesterol concrements in the gallbladder cavity. Cholesterolosis is a hyperplastic cholecistosis, caused by cholesterol accumulation in the gallbladder wall with subsequent proliferation of gallbladder normal tissue elements [1]. Variations in metabolism of lipids that lead to increases in serum total and low density lipoprotein (LDL) cholesterol, often to bile supersaturation with cholesterol, and possibly gallbladder hypomotility, have been implicated in gallstone and polyp formation $[2,3]$. The two disorders may be considered as a single disease, caused by impairment of cholesterol metabolism, but exhibiting different forms [4]. Both are clearly multi factorial disorders depending on both genetic and non genetic factors. Family and population studies have revealed a genetic predisposition in about $10-40 \%$ of patients with these diseases [5-7]. We describe a pair of monozygotic twins, one of whom developed gallstone disease and the other developed cholesterolosis. This illustrates the common genetic basis of both conditions. Differences between them may be explained by epigenetic, metabolic, or environmental factors.

\section{MATERIALS AND METHODS}

Two 40-year-old twin sisters (designated F. and P., respectively) were admitted to the Propedeutic Clinic of Internal Disease of the Moscow Sechenov Medical Academy, Moscow, Russia. Ultrasonograthy was done using convectional sensor PVF-375 MT 3,75 MHZ (Toshiba SSH-140A apparatus; Toshiba, Tochigi-Ken, Japan). The concentration of serum triglyceride and very 
low density lipoprotein (VLDL), LDL, high density lipoprotein (HDL) cholesterol were measured according to Folch et al. [8]. The subfraction spectrum of LDL was analyzed according to Krauss and Berke [9]. DNA was isolated by the standard method using proteinase K (Promega, Madison,WI, USA) and extraction with phenol-chloroform [10]. DNA fingerprinting with various microsatellite and minisatellite probes was carried out according to Limborska et al. [11]. DNA $(10 \mu \mathrm{g})$ was digested with Hinfl (Fermentas, Vilnius, Lithuania) and electrophoresed through $0.8 \%$ agarose gels. DNA was denatured, transferred to Hybond-N nylon membrane filters (Amersham Biosciences, Little Chalfont, Buckinghamshire, UK), and probed with ${ }^{32} \mathrm{P}-$ labeled oligonucleotides $(\mathrm{CAC})_{5}$ and (GATA) $)_{4}$. Blot hybridization was conducted in a mix of $6 \times$ sodium chloride/sodium citrate (SSC), $0.1 \%$ sodium dodecyl sulfate (SDS) and $10 \times$ Denhardt's solution $[0.5 \%$ polyvinylpyrrolidone; $0.5 \%$ Ficoll $400 ; 0.5 \%$ bovine serum albumin (BSA); Sigma, St Louis, MO, USA]. Filters were washed three times with $6 \times$ SSC for 30 $\mathrm{min}$. at room temperature, dried and autoradiographed at $-70^{\circ} \mathrm{C}$ for $1-3$ days with an EUI-1 intensifying screen (Renex, Moscow, Russia).

\section{RESULTS}

Patient F. complained of a dull abdominal pain, localized in the right upper quadrant, meteorism, nausea and bitter taste after eating. That was the patient's first episode of biliary colic. Laboratory biochemical study was normal; serum cholesterol level was $190 \mathrm{mg} / \mathrm{dL}$ [normal level (N): 150-190 mg/dL] and triglycerides were $98.4 \mathrm{mg} / \mathrm{dL}$ (N: 50-150 mg/dL), VLDL 19.7 $\mathrm{mg} / \mathrm{dL}(\mathrm{N}: 15-25 \mathrm{mg} / \mathrm{dL})$, LDL $111.3 \mathrm{mg} / \mathrm{dL}(\mathrm{N}$ : 110-131 mg/dL), HDL $59 \mathrm{mg} / \mathrm{dL}(\mathrm{N}: 27-89 \mathrm{mg} / \mathrm{dL}$ ); lipoprotein (a) $[\mathrm{Lp}(\mathrm{a})] 2 \mathrm{mg} / \mathrm{dL}$ (N: $<7.5 \mathrm{mg} / \mathrm{dL}$ ). The subfraction spectrum of LDL showed a predominance of minor dense particles of LDL [retardation factor (Rf) value $0.152 ; \mathrm{N}:<0.144]$. Ultrasonography showed an enlarged gallbladder with two echopositive structures, $7.0 \times 5.5$ and $8.0 \times 4.5 \mathrm{~mm}$, with acoustic shadows that were displaced on movement; the biliary content was not homogeneous (Fig. 1). Ultrasonography-based cholecystography revealed reduction in gallbladder motility, with a coefficient reduction of $38 \%(\mathrm{~N}: 65-$ $75 \%$ ). Sphincter of Oddi spasms lasted about $20 \mathrm{~min}$. The clinical diagnosis was gallstone disease, gallbladder hypotonia, sphincter of Oddi hypertonia.

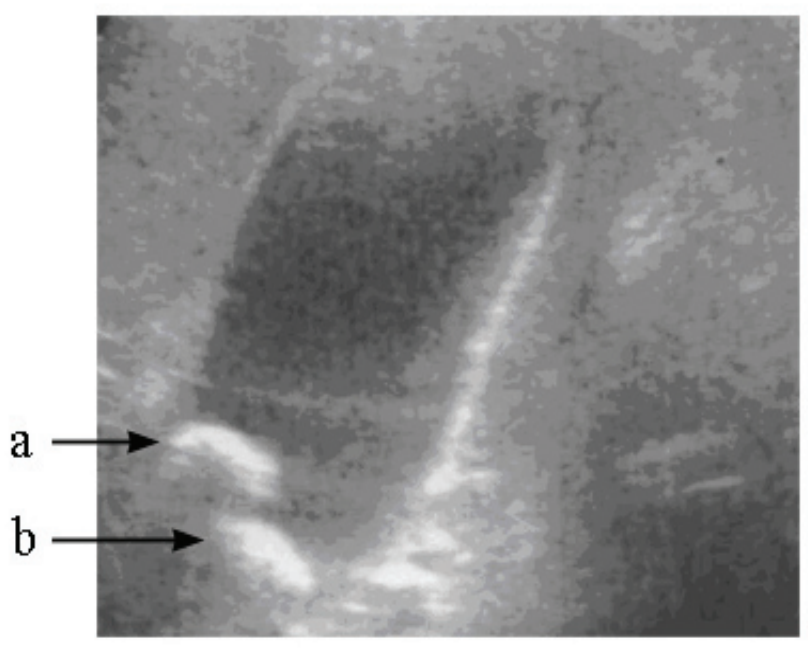

Figure 1. Ultrasonography of the gallbladder of patient F. The concretions measured $7.0 \times 5.5 \mathrm{~mm}$ (a) and $8.0 \times$ $4.5 \mathrm{~mm}$ (b).

Patient P. was admitted for polyposis in the gallbladder diagnosed by ultrasonography. She had no complaints and no episodes of biliary colic. However, the patient had experienced dyspepsia upon eating fatty foods. There was mild tenderness in the right upper quadrant on palpation. There was no hyperlipidemia and liver function tests (aspartate aminotransferase or alanine aminotransferase, alkaline phosphatase, and bilirubin levels) were normal. The total cholesterol level was $208 \mathrm{mg} / \mathrm{dL}$; triglycerides $43 \mathrm{mg} / \mathrm{dL}$; VLDL $10 \mathrm{mg} / \mathrm{dL}$; LDL $159 \mathrm{mg} / \mathrm{dL}$; HDL $46 \mathrm{mg} / \mathrm{dL}$; and $\mathrm{Lp}$ (a) $2 \mathrm{mg} / \mathrm{dL}$. The subfraction spectrum of LDL was characterized by predominance of minor dense particles (Rf value 0.157). Ultrasonography showed a hypertrophied gallbladder wall, $3.0-5.0 \mathrm{~mm}$ thick, with several echopositive structures lacking acoustic shadows (polyps) and measuring 6.0 and $4.0 \mathrm{~mm}$ on the front wall and 4.3 and $3.8 \mathrm{~mm}$ on the other wall, without displacement on movement, the bile was not homogeneous (Fig. 2). Ultrasonography-based cholecystography revealed normal motility function of the gallbladder, with a coefficient reduction of $67 \%$; sphincter of Oddi spasms lasted about $5 \mathrm{~min}$. The clinical diagnosis was cholesterolosis of gallbladder. Family history revealed that the patients' father had experienced gallstone disease and surgery for cholesterol cholelithiasis.

For precise determination of twin zygosity, the DNA fingerprinting with various microsatellite and minisatellite probes was used [11]. Figure 3 shows typical results of DNA fingerprinting in dizygotic twins 


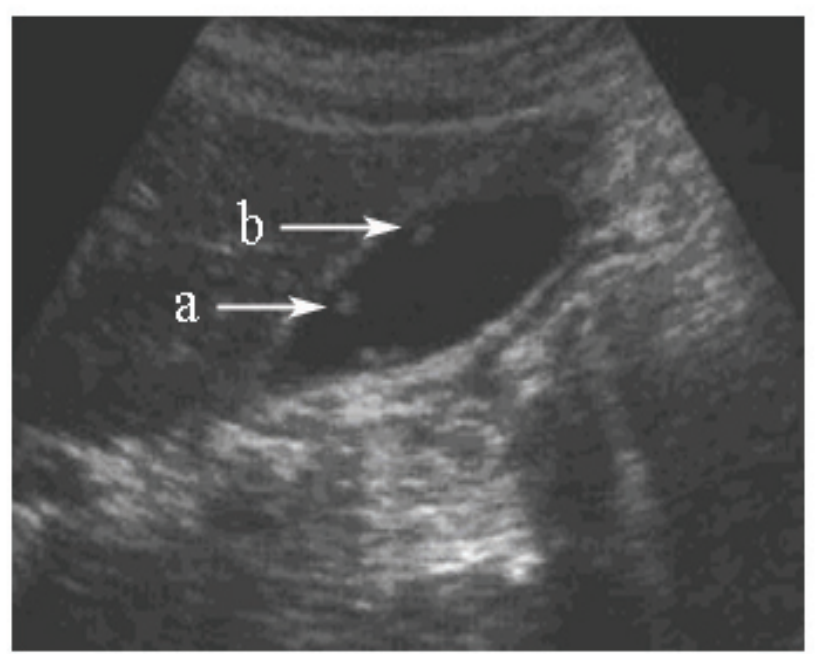

Figure 2. Ultrasonography of the gallbladder of patient P. The echopositive structures measured $6.0 \mathrm{~mm}$ (a) and $4.0 \mathrm{~mm}$ (b).

(lanes 1 and 2) taken as controls and patients F. and P. (lanes 3 and 4). Two microsatellite core probes, $(\mathrm{CAC})_{5}$ and (GATA), used for the analysis, produced different patterns in dizygotic twins and identical fingerprint patterns in patients F. and P. Similar results were also obtained when microsatellite oligonucleotide probes $(\mathrm{GACA})_{4},(\mathrm{TCC})_{50}$ and minisatellite core probes M13 and Jeffreys 33.15 were used for such analyses (not shown). The identity of fingerprints obtained for F. and P. proves that these two patients were monozygotic twins.

A
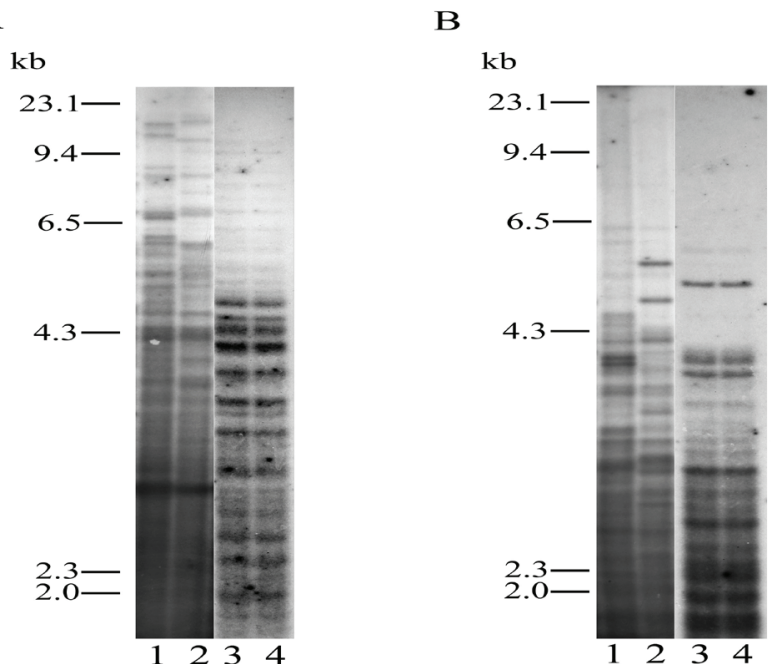

Figure 3. Zygosity determination using DNA fingerprinting. Lanes 1 and 2: dizygotic twin controls; lane 3: patient F; lane 4: patient P. HindIII fragments of $\lambda$ phage DNA were used as molecular weight markers. A: (CAC) probe; B: (GATA) ${ }_{4}$ probe.

\section{DISCUSSION}

Impaired cholesterol metabolism appears to be the primary factor [2] in the formation of cholesterol gallstones and polyps in the gallbladder [12]. A prerequisite for their development is accumulation of cholesterol in the bile, causing cholesterol supersaturation. This often, but not always, reduces gallbladder motility because of excessive accumulation of cholesterol esters within epithelial macrophages of the gallbladder wall and formation of foam cells (cholesterolosis). Gallbladder dysfunction is caused by cholesterol action on sarcoleme membrane of the gallbladder smooth muscles [13]. However, some patients with cholesterolosis have a normal functioning gallbladder, as in the case of patient $\mathrm{P}$. Cholesterol in bile is accumulated as micelles and vesicles under normal physiologic conditions. Supersaturated mono lamellar vesicles coalesce into multi lamellar vesicles and liposomes (liquid crystals), which transform into solid mono crystals of cholesterol [14]. Gallbladder hypomotility reduces the enterohepatic circulation and increases the aggregation of bile components. The monozygotic twin patients described here indicate a common genetic basis for their gallstone disease and cholesterolosis.

Many studies indicate that gallstone susceptibility has genetic components [5-7,15]. The genetic polymorphisms in various genes for apo $\mathrm{E}$, apo $\mathrm{B}$, apo A1, LDL receptor, cholesterol ester transfer and LDL receptor-associated protein, have been implicated in gallstone and polyp formation.

Kesaniemi et al. [16] have studied the relative contribution of genetic factors to biliary and serum lipid composition in 17 monozygotic and 18 dizygotic middle-aged pairs of twins. Their data suggest that molar percentage of biliary cholesterol, bile acid composition, cholesterol synthesis, bile cholesterol saturation and gallstone formation may be under significant genetic control.

Determination of zygosity may be done by comparison of physical characteristics, blood group or tissue typing, chromosome studies, or examination of various other polymorphic protein markers. However, all these markers may not be uniformly informative. Here, we used a multi locus DNA fingerprinting method for determining the twin zygosity of our patients. This method uses microsatellite or minisatellite core probes [11], requires only a small amount of DNA, and detects the restriction fragment length polymorphisms (RFLP) 
which are a result of allelic differences in the loci that contain the core sequences. The DNA fingerprinting analysis revealed that patients F. and P. were indeed monozygotic twins. Both had a predominance of minor dense particles of LDL, but different forms of cholesterol accumulation (gallstone disease in one and cholesterolosis in the other). Patient F. showed marked hypotonya of gallbladder and hypertonya of sphincter of Oddi. But in patient P., we observe the normal function of the gallbladder and sphincter Oddi. We conclude that heterogeneity of the LDL fraction in patient F. resulted in aggregation of supersaturated bile with formation of gallstones, and that the normal gallbladder function in patient P. led to passive and active cholesterol absorption.

At present, it is unclear why in some patients cholesterol accumulation occurs in the gallbladder wall (cholesterolosis), and in others it occurs in the gallbladder cavity (gallstone disease). We conclude that gallstone disease and cholesterolosis showing identical changes in the plasma LDL subfraction may be caused by different functional conditions within the gallbladder, which may be due to epigenetic, metabolic or environmental factors, since both diseases have a common genetic basis.

\section{ACKNOWLEDGMENTS}

This study was supported in part by the Russian Academy Science Program on Molecular and Cell Biology and the President of Russian Federation Program of Leading Scientific Schools (Moscow, Russia).

\section{REFERENCES}

1. Jacyna M, Bouchier I. Cholesterolosis: a physical cause of "functional" disorder. Br. Med J 1987; 295(12): 619-620.

2. Stromsten A, von Bahr S, Bringman S, Saeki M, Sahlin S, BjorkhemI, Einarsson C. Studies on the mechanism of accumulation of cholesterol in the gallbladder mucosa. Evidence that sterol 27-hydroxylase is not a pathogenetic factor. J Hepatol 2004; 40(1): 8-13.

3. van Berge-Henegouwen $G$, Venneman $N$, Portincasa P, Kosters A, van Erpecum K, Groen A. Relevance of hereditary defects in lipid transport proteins for the pathogenesis of cholesterol gallstone disease. Scand J Gastroenterol 2004; 39(Suppl 241): 60-69.
4. Palot J, Pluot M, Delattre J, Remy G. Is vesicular cholesterolosis a particular anatomo-clinical form of cholesterol lithiasis? Apropos of a case of cholesterol polyp manifested by an acute complication. J Chirurg 1986; 123(8-9): 4676-471.

5. Kosters A, Jirsa M, GroenA. Genetic background of cholesterol gallstone disease. Biochim Biophys Acta 2003; 1637(1): 1-19.

6. Sarin S, Negi V, Dewan R, Sasan S, Saraya A. High familial prevalence of gallstones in the firstdegree relatives of gallstone patients. Hepatology 1995; 22(1): 138-141.

7. Weiss K, Ferrell R, Hanis C, Styne P. Genetics and epidemiology of gallbladder disease in New World native peoples. Am J Hum Genet 1984; 36(6): 12591278.

8. Folch I, Lees M, Stanley S. A simple method for the isolation and purification of total lipids from animal tissues. J Biol Chem 1959; 226(1): 497-509.

9. Krauss R, Berke D. Identification of multiple subclasses of plasma low density lipoproteins in normal humans. J Lipid Res 1982; 23(1): 97-104.

10. Mathew C. The isolation of high molecular weight eukaryotic DNA. In: Walker J, Ed. Methods in Molecular Biology. New York: Humana, 1984; 31-34.

11. Limborska S, Prosnyak M, Bocharova T, Smirnova E, Ryskov A. The properties of human DNA fingerprints produced by polymeric monocore probes (PMC probes). Genet Anal Biomolec Eng 1999; 15(1): 19-24.

12. Tilvis R, Miettinen T. Sgualene, methylsterol and cholesterol levels in human organs; posmorten analysis of their distribution. Arch Pathol Lab Med 1980; 104(1): 35-40.

13. Xu Q, Shaffer A. The potential site of impaired gallbladder contractility in animal model of cholesterol gallstone disease. Gastroenterology 1996; 110(1): 251257.

14. Carey M. Pathogenesis of gallstones. Am J Surg 1993; 165(4): 410-419.

15. Juvonen T, Savolainen J, Kairaluoma M, Lajunen L, Humphries S, Kesaniemi Y. Polymorphisms at the apo B, apo A-1, and cholesteryl ester transfer protein gene loci in patients with gallbladder disease. $\mathrm{J}$ Lipid Res 1995; 36(4): 804-816.

16. Kesaniemi A, Koskenvuo M, Vuoristo M, Miettinen T. Biliary lipid composition in monozygotic and dizygotic pairs of twins. Gut 1989; 30(12): 17501756. 